\title{
Should a water colour parameter be included in lake total phosphorus prediction models used for the Water Framework Directive?
}

\author{
Susan I. Vinogradoff and Ian W. Oliver ${ }^{\star} \neq$ \\ Scottish Environment Protection Agency (SEPA), Avenue North, Heriot-Watt Research Park, Edinburgh, \\ UK, EH14 4AP \\ * corresponding author: lan.Oliver@alumni.adelaide.edu.au \\ ${ }^{\ddagger}$ current address: School of Physical \& Geographical Sciences, Keele University, Staffordshire, UK, ST5 \\ $5 B G$
}

\begin{abstract}
Under the Water Framework Directive (WFD) lakes are classified according to a variety of criteria. This classification facilitates state of the environment assessments and helps identify work needed to achieve the objectives of the WFD, which are broadly to maintain and/or restore water quality and ecological status at a level recognised as good or high. To achieve high or good status, lakes must meet a criterion for total phosphorus (TP) that is linked to a predicted reference condition value that is derived by various models. Lakes which fail to meet good status may require expensive remedial actions to be undertaken, thus accurate identification of the reference condition TP concentration is vital for effective environmental management. However, the models currently employed could be improved for some regions, particularly those with carbon rich soils. By examining 19 reference condition lakes (i.e. lakes essentially non-impacted by humans) in peaty areas of Scotland, we found that a simple parameter linked to water colour and humic substances was a better predictor of TP than the currently employed models $\left(R^{2} 0.585\right.$ vs $\left.R^{2}<0.01\right)$. Therefore, for Scotland and elsewhere, in regions with carbon rich soils and lakes with humic waters the TP predictive models could be improved by development and incorporation of a parameter related to water colour and humic components.
\end{abstract}

Keywords: nutrients; DOC; Hazen; River Basin Management Planning; unit conversion; SEPA

\section{Introduction}

Under the European Union's Water Framework Directive (WFD)(EC, 2000) lakes are classified for environmental status using a range of ecological and chemical water quality parameters. In many member states (i.e. EU member countries) part of the classification process involves assessing total phosphorus (TP) concentration against quality thresholds (corresponding to high, good, moderate, poor or bad status) that are determined according to a site specific or lake type specific TP reference condition. The TP reference condition is intended to reflect undisturbed or minimally impacted conditions (Stoddard et al., 2006). Lakes that do not meet the set criteria for TP cannot be classified as having good ecological status, which is one of the goals set for waterbodies under the WFD, thus failures may lead to environment improvement actions having to be undertaken. Under the WFD, TP reference conditions are commonly determined according to models 
developed by Cardoso et al (2007) from a large dataset of >500 European reference lakes (lakes considered to have no or only very limited anthropogenic input of phosphorus) that were gathered together via the European Commission (EC) FP6 Project REBECCA (EC, 2005). The models attempt to take account of catchment geographical variables (geology, elevation, region) as well as lake characteristics (i.e. water depth, water chemistry and lake size/area). Differing models were derived for the various Geographical Intercalibration Groups (GIGs; i.e. regions established for the purposes of the WFD intercalibration exercise, see Van de Bund et al., 2004 and Carvalho et al. 2008) and model subtypes for humic and non-humic water conditions were derived in an attempt to address the recognised (though poorly understood) potential influence of humic substances on nutrient levels and planktonic primary production (Cardoso et al., 2007; Nurnberg and Shaw, 1998). However, the dataset upon which the models were based did not include high elevation lakes (>800 $\mathrm{m}$ aod) and only a very limited number of lakes from peat-rich (or $\mathrm{C}$ rich) zones. Also, lakes with annual mean TP concentrations above $35 \mu \mathrm{g} / \mathrm{L}$ were excluded from the dataset even if they were otherwise identified as meeting reference condition criteria. Valid reasons were presented for this exclusion (Cardoso et al., 2007), but the consequence was that lakes with naturally high TP were under represented or absent in model development.

Assessment of the derived models against measured concentrations revealed that they were able to account for $\sim 51 \%$ of the variance in TP concentrations for the lakes in the reference lake dataset, demonstrating that whilst they were more (or at least no less) powerful predictors than previous models based on diatom and chironomid data (Bradshaw and Anderson, 2001; Brooks et al., 2001) they did have a degree of remaining uncertainty (Cardoso et al., 2007). This left the model developers to conclude that further validation and testing of the models was needed, perhaps using independent test sets of lakes at reference condition. 
The Northern and Atlantic TP predictor models are used in Scotland and the non-humic model (Eq 1), employing elevation (altitude) and morphoedaphic index as independent predictors, is currently applied for the derivation of reference TP conditions for lakes in Scotland (which are generally referred to as 'lochs') under WFD where sufficient data allow (Scottish Government, 2009). Morphoedaphic index is the ratio between total dissolved solids (edaphic factor) in lake water (as measured by alkalinity, m equivalents/L) to the lake mean depth in metres (morphometric factor) (Cardoso et al., 2007). The humic version of the model (Eq 2) is not currently used for WFD purposes in Scotland (Scottish Government, 2009), but with a better understanding of how humic substances influence TP levels in natural settings it may be possible to derive an improved model that successfully incorporates a humic related parameter. One additional impediment to such improvements is the lack of standardisation in humic water definitions and thus identification of exactly where a humic model should apply (see Table 1).

$$
\begin{array}{ll}
\text { Non humic model: } \log (T P)=1.36(0.03)-0.09(0.02) \log (\text { alt })+0.24(0.06) \log \left(M_{E} l_{a l k}\right) & \text { Eq } 1 \\
\text { Humic model: } \log (T P)=1.62(0.12)-0.09(0.02) \log (\text { alt })+0.24(0.06) \log \left(M I_{a l k}\right) & \text { Eq } 2
\end{array}
$$

where TP = total phosphorus, $\mu \mathrm{g} / \mathrm{L}$; alt = altitude or elevation, $\mathrm{m} ; \mathrm{MEl}_{\mathrm{alk}}=$ Mophoedaphic index.

Models are valuable for environmental regulation of waterbodies because they are simple to implement and are generally based on comprehensive supporting data, such as the large (>500 EU lakes) dataset. However, whilst useful, the existing TP models could be improved (i.e. in terms of predictive strength) for some EU member states because of local or regional factors. For example, in Scotland there are many upland regions and areas with highly $\mathrm{C}$ rich soils and peat that may influence the natural levels of phosphorus present in lochs. According to the WFD 2010 loch classifications (SEPA, 2012) 62 Scottish lochs failed to meet the TP standard for good status, which in each case could potentially necessitate development and implementation of remedial action (i.e. environment improvement actions). Therefore, if TP reference conditions are underestimated by the predictor models the failing lochs may have their status incorrectly 
downgraded and, if so, any corrective action undertaken may not be truly warranted or even desirable (i.e. in terms of natural ecology of a site).

In this study we examined the utility of the currently employed clear model and the humic alternative for predicting TP reference conditions in Scottish lochs by first investigating the predicted versus measured TP concentrations in 19 lochs that are at reference condition (i.e. close to pristine). We then assessed the possible utility of an additional model parameter linked to humic substance concentration: water colour and/or UV-vis light absorbance and/or dissolved organic carbon, DOC, the relationships between which have been demonstrated in freshwater lakes (e.g. Nürnberg and Shaw 1998) and have been successfully exploited in other fields (e.g. Farmer et al., 2002; Graham et al., 2006; Jackson et al., 2005; Oliver et al., 2008). Finally, based on loch water characteristics, we assessed how applicable an expanded model may be for all WFD-classified lochs in Scotland. Given the widespread and increasing use of predicted reference nutrient conditions within environmental assessment programmes, e.g. within the EU (EC, 2000; Phillips et al., 2008), USA (USEPA, 2000) and recently China (Huo et al., 2012), wide applicability of our results is anticipated.

\section{Methods}

\subsection{Reference condition lochs and current model evaluation}

A set of 19 reference condition lochs (Figure 1 and Table 2) from peat or $\mathrm{C}$ rich soil areas was identified from the network of lochs monitored by the Scottish Environment Protection Agency (SEPA). Because of the monthly monitoring programme, sufficient measured TP and associated data were available for each loch to satisfy the original data requirements used in the compilation of the larger European reference lake dataset (Cardoso et al., 2007). TP data for the 19 reference lochs, primarily within the years 2007-2009, were extracted from the water monitoring archive and evaluated against the TP reference conditions predicted by the models (Eq 1 and Eq 2). To 
maintain consistency with the original data specifications employed in derivation of the prediction models (Cardoso et al., 2007), data from the April-September time period was used to calculate average values for the lochs. The analytical method used to determine TP followed standard methods (GB-SCA, 1992) and was supported by full laboratory QA/QC measures and United Kingdom Accreditation Service (UKAS) accreditation. All reagents used were of analytical grade.

\subsection{Hazen and UV-vis absorbance unit inter-conversion}

For sites to be categorized according to the GIG-IC lake typologies (Table 1) and thus allow assigning to humic categories to facilitate assessment of the TP predictor models, an equation was derived for inter-converting colour in Hazen units (now largely historical) with UV-vis absorbance units at 254 and $400 \mathrm{~nm}$ wavelengths (i.e. the SEPA national colour determination method, following GB-SCA, 1984). The Hazen standard unit is defined as the colour produced by $1 \mathrm{mg} / \mathrm{L}$ platinum $(\mathrm{Pt})$ in the form of chloroplatinic acid $\left(\mathrm{H}_{2} \mathrm{PtCl}_{6}\right)$ in the presence of $2 \mathrm{mg} / \mathrm{L}$ cobaltous chloride hexahydrate $\left(\left[\mathrm{CoCl}_{2}\left(\mathrm{H}_{2} \mathrm{O}\right)_{4}\right] \cdot 2 \mathrm{H}_{2} \mathrm{O}\right)(\mathrm{GB}-\mathrm{SCA}, 1984)$. A 100 Hazen standard $\left(5.12 \times 10^{-4} \mathrm{M}\right.$ Pt) in a $50 \mathrm{~mm}$ cell has an absorbance at $400 \mathrm{~nm}$ of $0.4515 \mathrm{a} . \mathrm{u}$, which can be used to determine the molar absorptivity using the Beer-Lambert Law: $A=\varepsilon . c . I \quad$ (where $A=$ absorbance, $\varepsilon=$ molar absorptivity in $\mathrm{L} / \mathrm{mol} / \mathrm{cm}, \mathrm{c}=$ molar concentration and $\mathrm{I}=$ light path length in $\mathrm{cm}$ ). This yields a molar absorptivity of $\varepsilon=176.252 \mathrm{~L} / \mathrm{mol} / \mathrm{cm}$. Using the molar mass of Pt and rearranging the BeerLambert Law thus yields the Hazen - UV-vis absorbance conversion (Eq 3).

$$
\text { Concentration }(\mathrm{mg} \mathrm{Pt} / \mathrm{L} \text {, Hazen units })=[\text { A } 400 \mathrm{~nm} / \mathrm{I}(\text { in cm) }] \times 1106.848 \quad \text { Eq. } 3
$$

\subsection{UV-vis absorbance and DOC relationship}

UV-vis absorbance data for the lochs in the Scottish reference loch database was insufficient to assign all 19 lochs to humic categories according to the GIG-IC lake typologies (after conversion from Hazen units), thus the relationship between UV-vis absorbance and DOC concentration for all lochs monitored across Scotland was examined in order to determine whether the parameters 
could be used as surrogates for each other. This had the potential added benefit of allowing lochs (both in the reference loch database and more widely) to be assigned into humic categories based on both the colour and the DOC classification systems (Table 1). Such relationships between DOC and UV-vis absorbance have been relied upon previously (Farmer et al., 2002; Graham et al., 2006; Jackson et al., 2005; Oliver et al., 2008), as DOC can be one of the principal components that give rise to colour in natural waters.

Within the full SEPA loch monitoring network, paired DOC $(0.45 \mu \mathrm{m}$ filtered) and UV-vis absorbance (250 and $400 \mathrm{~nm}$ ) data were available for $>200$ lochs. Data were extracted for the period January 2009 to February 2010, annual average absorbance and DOC values were then determined and regressions of mean DOC vs mean absorbance were performed. The relationship was strong and positive between DOC and light absorbance at both wavelengths $254 \mathrm{~nm}\left(\mathrm{R}^{2}=\right.$ 0.878, $\mathrm{p}<0.0001, \mathrm{n}=225)$ and $400 \mathrm{~nm}\left(\mathrm{R}^{2}=0.756, \mathrm{p}<0.0001, \mathrm{n}=225\right)$ (Figure 2), justifying their use as surrogates when necessary. The DOC-UV-vis absorbance relationship was comparable to a previously identified relationship between total organic carbon (TOC) and UV-vis absorbance $\left(R^{2}=0.964\right)$ (Graham et al., 2006). The conversion equations derived for UV-vis absorbance and DOC were (see Figure 2):

$$
\begin{array}{ll}
\text { UV-vis abs } 254 \mathrm{~nm}=0.208 \mathrm{DOC}(\mathrm{mg} / \mathrm{L})-0.207 & \text { Eq. } 4 \\
\text { UV-vis abs } 400 \mathrm{~nm}=0.029 \mathrm{DOC}(\mathrm{mg} / \mathrm{L})-0.036 & \text { Eq. } 5
\end{array}
$$

Relationships between DOC/UV-vis absorbance/colour and measured TP concentrations in the 19 reference lochs were then examined via linear regressions to determine their likely predictive power (i.e. for possible use as an additional parameter in future TP reference condition predictor models). 


\subsection{Scottish loch categorisation}

The relationships derived between UV-vis absorbance and DOC and the inter-conversion developed for absorbance and Hazen units were used to assign all monitored lochs across Scotland (of those with sufficient data) into humic categories according to both the Hazen and DOC criteria (i.e. Table 1).

\section{Results and discussion}

\subsection{Measured vs Predicted TP concentrations}

Mean measured TP concentrations for the 19 reference lochs were not well predicted by either the humic or non-humic models (Figure 3), with $\mathrm{R}^{2}$ values for log-log plots well below 0.01 and $p$ $>0.91$. A much better, though still less than desirable, predictive power for the models was noted in a Finnish study of 69 lakes with colour $(\mathrm{Hz})$ and TP concentrations comparable to those of the 19 Scottish lochs examined here ( $R^{2}$ 0.489; Heikki Mykrä, Ministry of the Environment, Finland, pers comm. of unpublished data 2008; see Fig.SI-1, supporting information). The Finnish study observed an increase in TP model residuals with increasing water colour, which we also found in the present investigation along with an increase in residuals associated with increasing TP concentrations (Figure 4).

\subsection{Relations between measured TP concentrations and DOC/colour}

The increasing TP model residuals associated with increasing water colour (determined from the DOC - UV-vis relationship and Eq 3), as shown in Figure 4, indicated that water colour or a surrogate parameter may have high predictive power for mean lake TP concentrations in peaty or C rich soil areas. A regression of mean measured TP against water colour found this to be so, returning an $\mathrm{R}^{2}=0.585$ with $\mathrm{p}<0.0001$ (Figure 5). The regression indicates that colour (or a surrogate) alone was able to predict TP concentrations in the 19 reference lochs more precisely 
than the models currently used. Moreover, the predictive power of the colour parameter $\left(\mathrm{R}^{2}=\right.$ 0.585) compares favourably with the over-all TP variance accounted for by the various models developed by Cardoso et al.(2007) from the large EU lake dataset (c.f. $~ 51 \%$ of the variance in TP). This would suggest that a water colour-related parameter should be incorporated into an updated predictive model for lakes from peat or $\mathrm{C}$ rich soil areas. In order to maximise the precision and reliability of such an updated model, it will therefore be necessary to identify the most appropriate parameter to use. UV-vis absorbance or DOC concentration have been identified here, but further research into the nature of humic substances that are most associated with TP may reveal parameters with greater predictive power. This is particularly important when considering that although the DOC surrogate used here was highly correlated with colour $\left(\mathrm{R}^{2}\right.$ 0.878, $\mathrm{p}<0.0001, \mathrm{n}=225)$, some variance remained unaccounted for. Nürnberg and Shaw (1998) similarly found DOC and colour to be highly significantly related $\left(R^{2} 0.64, n=212\right)$ but with some remaining variance $(\sim 1 / 3)$ left unexplained. Therefore, the derivation of a new colour-based parameter for an improved TP prediction model may require the identification of a particular component within humic substances that has greater predictive power than DOC alone. The effect of seasonality, which has been shown to influence phosphorus delivery to and dynamics in lakes (e.g. Jordan et al., 2012), on such a parameter would also have to be considered. Any new parameter would also need to be robust and unaffected (or affected to a quantifiable degree) by changing pressures on lakes, including recovery from acidification and changes linked to climate shifts that may affect humic components.

\subsection{Scottish loch categorisation and wider applicability of the humic parameter}

Using the inter-relationships derived here between DOC, colour and UV-vis absorbance, it was possible to assess the data from 255 monitored lochs across Scotland and subsequently assign each of them to humic or non-humic categories according to the criteria set down in Table 1. This identified $61-67 \%$ of the lochs as humic (depending on which categorisation system was 
considered). Together with the links between humic substances and TP confirmed in this study, this finding highlights the improvements that could be gained by taking better account of humic substances in TP predictor models applied in Scotland and in other regions where humic waters occur with high frequency. Improved models could then even be combined with other emerging techniques, such as nutrient impact assessment in lakes by chironomid pupal exuviae evaluation (Ruse, 2010), to better determine the environmental status of lakes and identify where remediation may be warranted.

\section{Conclusions}

Current models used to predict TP reference conditions for lakes under WFD could be improved (i.e. made to have increased predictive strength) for zones with high amounts of peat or $\mathrm{C}$ rich soils because the models do not fully take into account the influence of humic substances and water colour on natural TP levels. Therefore, the introduction of an explanatory parameter that reflects the important component(s) of humic substances could improve the predictive power of the models for such areas. Future work is thus required to better understand and characterise the water colour-humic substance-TP relationship in the context of ecological status, so that a new parameter can be derived for inclusion in an improved model for use in lake status classification.

\section{Acknowledgements}

The authors are grateful to the many SEPA field and laboratory staff who collected and analysed water samples. In addition, we thank lan Fozzard, Willie Duncan and Ashley Roberts (SEPA) as well as Paul Edmonds (Environment Agency, UK) for valuable discussions in relation to this work. The generosity of Heikki Mykrä (Ministry of the Environment, Finland), in relation to data sharing, is gratefully acknowledged. 


\section{Disclaimer}

Any opinions expressed in this paper are those of the authors and are not necessarily those of the host organisation (SEPA).

\section{References}

Bradshaw, E.G., John Anderson, N., 2001. Validation of a diatom-phosphorus calibration set for Sweden. Freshwater Biology 46, 1035-1048.

Brooks, S.J., Bennion, H., Birks, H.J.B., 2001. Tracing lake trophic history with a chironomid-total phosphorus inference model. Freshwater Biology 46, 513-533.

Cardoso, A.C., Solimini, A., Premazzi, G., Carvalho, L., Lyche, A., Rekolainen, S., 2007. Phosphorous reference conditions in European Lakes. Hydrobiologia 584, 3-12.

Carvalho, L., Solimini, A., Phillips, G., van den Berg, M., Pietiläinen, O-P., Solheim, AL., Poikane, S., Mischke, U. Chlorophyll Reference Conditions for European Lake Types used for Intercalibration of Ecological Status. Aquatic Ecology 2008; 42: 203-211.

European Commission, 2005, Relations between ecological and chemical status of surface waters (REBECCA). FP6 Project. http://www.rbm-toolbox.net/rebecca/index.php.

European Commission, 2000, Directive 2000/60/EC (the Water Framework Directive) of the European Parliament and of the Council of 23 October 2000 establishing a framework for Community action in the field of water policy. Official Journal of the European Commission L327 (2000) 1.

Farmer, J.G., Thomas, R.P., Graham, M.C., Geelhoed, J.S., Lumsdon, D.G., Paterson, E., 2002. Chromium speciation and fractionation in ground and surface waters in the vicinity of chromite ore processing residue disposal sites. Journal of Environmental Monitoring 4, 235-243. 
GB-SCA; Great Britain-Standing Committee of Analysts, 1984. Methods for the examination of waters and associated materials: Colour and turbidity of waters (blue book 103). HMSO, London.

GB-SCA; Great Britain-Standing Committee of Analysts, 1992. Methods for the Examination of Waters and Associated Materials: Phosphorus and Silicon in Waters, Effluents and Sludges (blue book 147). HMSO, London.

Graham, M.C., Vinogradoff, S.I., Chipchase, A.J., Dunn, S.M., Bacon, J.R., Farmer, J.G., 2006. Using size fractionation and $\mathrm{Pb}$ isotopes to study $\mathrm{Pb}$ transport in the waters of an organicrich upland catchment. Environmental Science \& Technology 40, 1250-1256.

Huo, S., Zan, F., Chen, Q., Xi, B., Su, J., Ji, D., Xu, Q., 2012. Determining reference conditions for nutrients, chlorophyll a and Secchi depth in Yungui Plateau ecoregion lakes, China. Water and Environment Journal.

Jackson, B.P., Ranville, J.F., Bertsch, P.M., Sowder, A.G., 2005. Characterization of colloidal and humic-bound $\mathrm{Ni}$ and $\mathrm{U}$ in the "dissolved" fraction of contaminated sediment extracts. Environmental Science \& Technology 39, 2478-2485.

Jordan, P., Melland, A.R., Mellander, P.E., Shortle, G., Wall, D., 2012. The seasonality of phosphorus transfers from land to water: Implications for trophic impacts and policy evaluation. Science of the Total Environment 434, 101-109.

Nürnberg, G.K., Shaw, M., 1998. Productivity of clear and humic lakes: Nutrients, phytoplankton, bacteria. Hydrobiologia 382, 97-112.

Oliver, I.W., Graham, M.C., MacKenzie, A.B., Ellam, R.M., Farmer, J.G., 2008. Depleted uranium (DU) mobility across a weapons testing site: Isotopic investigation of porewater, earthworms and soil. Environmental Science \& Technology 42, 9158-9164. 
Phillips, G., Pietiläinen, O.-P., Carvalho, L., Solimini, A., Lyche Solheim, A., Cardoso, A.C., 2008. Chlorophyll-nutrient relationships of different lake types using a large European dataset. Aquatic Ecology 42, 213-226.

Ruse, L., 2010. Classification of nutrient impact on lakes using the chironomid pupal exuvial technique. Ecological Indicators 10, 594-601.

SEPA, 2012. Water Monitoring and Classification under WFD, 2010 report. http://www.sepa.org.uk/water/monitoring and classification.aspx

Scottish Government, 2009. Scotland River Basin District (Surface Water Typology, Environmental Standards, Condition Limits and Groundwater Threshold Values) Directions 2009.

Stoddard, J.L., Larsen, D.P., Hawkins, C.P., Johnson, R.K., Norris, R.H., 2006. Setting expectations for the ecological condition of streams: The concept of reference condition. Ecological Applications 16, 1267-1276.

USEPA, 2000. Nutrient Criteria Technical Guidance Manual Lakes and Reservoirs EPA-822-B00001. Office of Water, Office of Science and Technology, USEPA, Washington.

Van de Bund, W., Cardoso, A.C., Heiskanen, A.S., Noges, P., 2004. Overview of Common Intercalibration Types.

FIGURES \& TABLES FOLLOW 


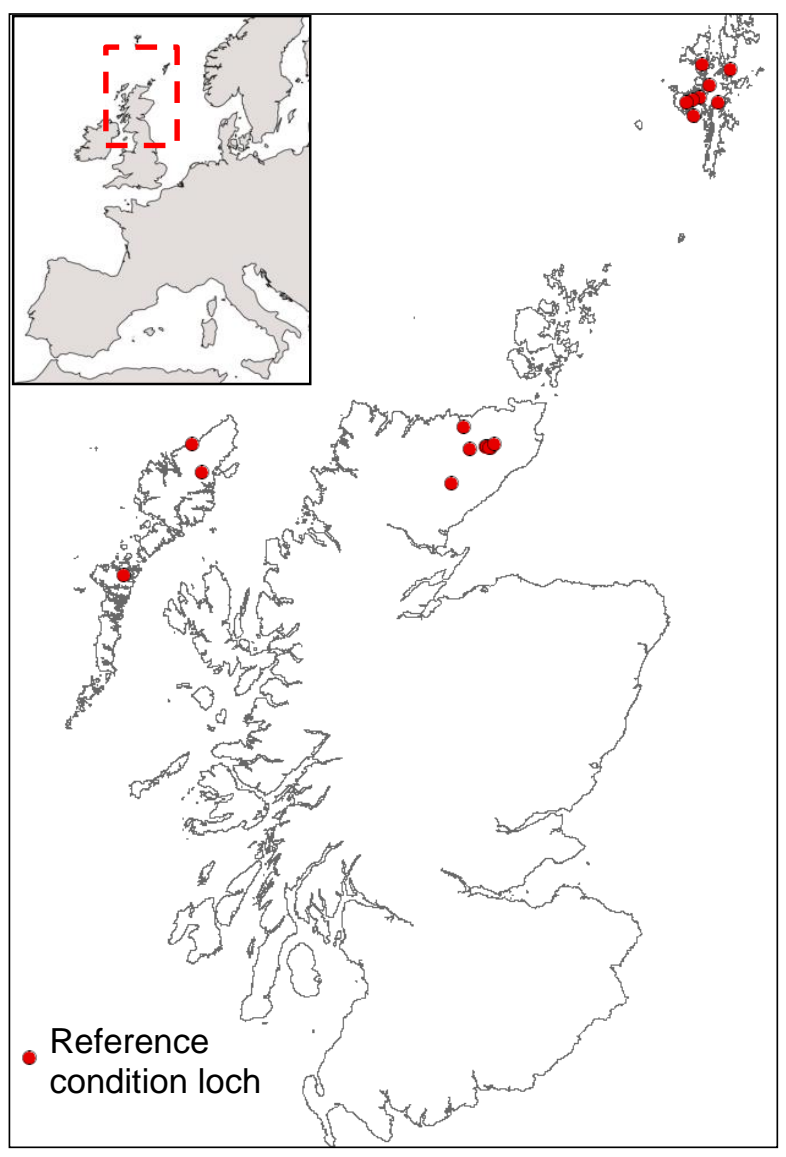

Figure 1. Map of Scotland showing locations of the 19 lochs in the reference condition loch database (inset: Western Europe, indicating the relative position of Scotland). 


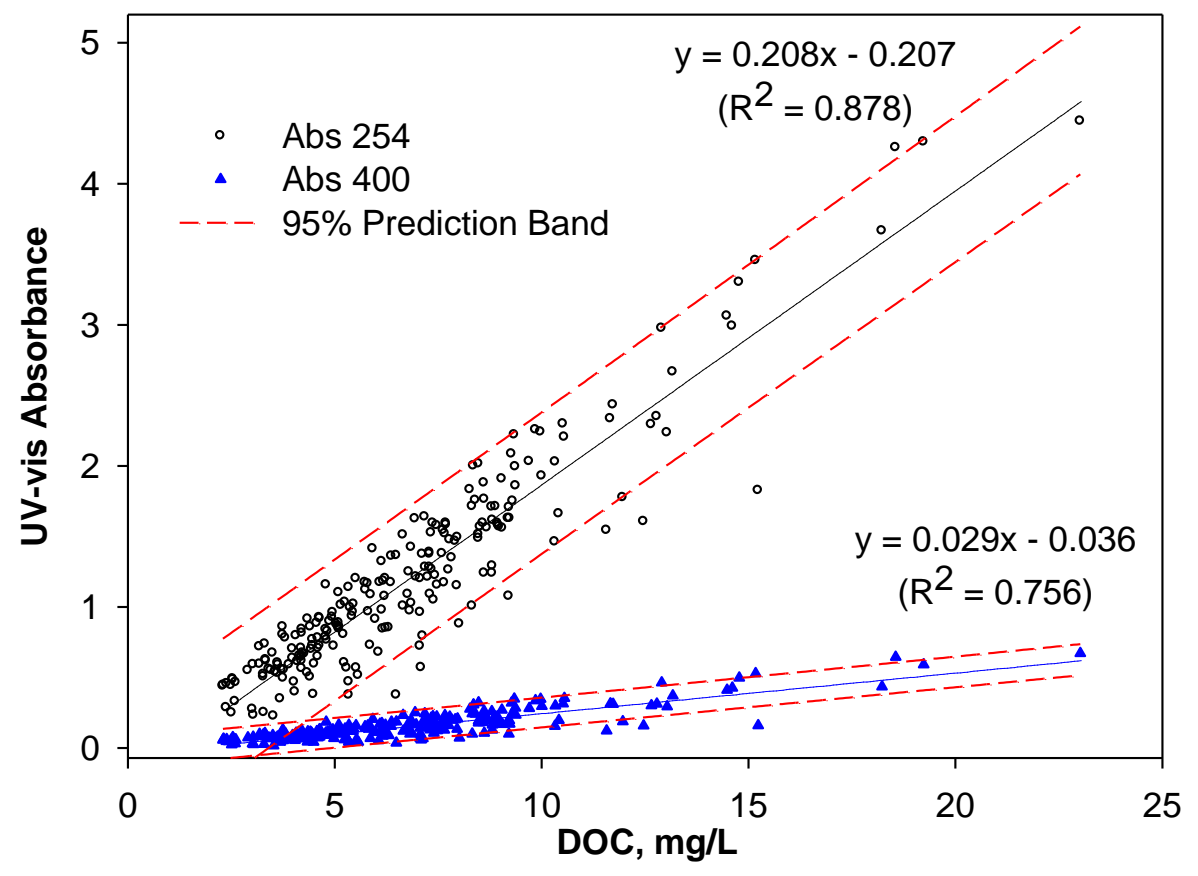

Figure 2. Regressions of annual mean dissolved organic carbon (DOC, $0.45 \mu \mathrm{m}$ ) vs annual mean UV-vis absorbance at 254 and $400 \mathrm{~nm}$ for a dataset of $>200$ Scottish lochs. Both regressions had $p<0.0001$. 


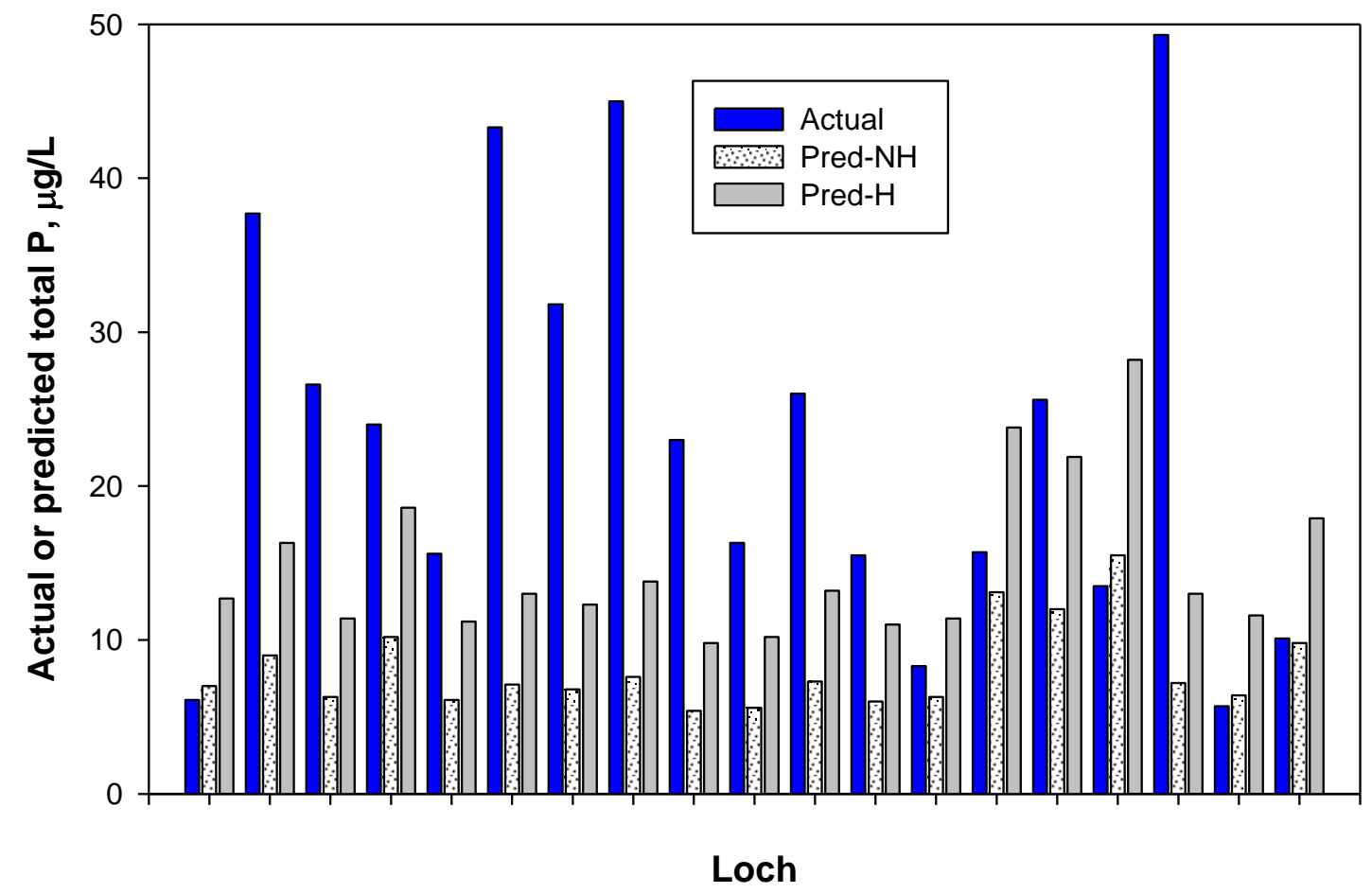

Figure 3. Measured vs predicted total phosphorus (TP) concentrations for the humic and non-humic models. Neither model provided a good fit for the data. 


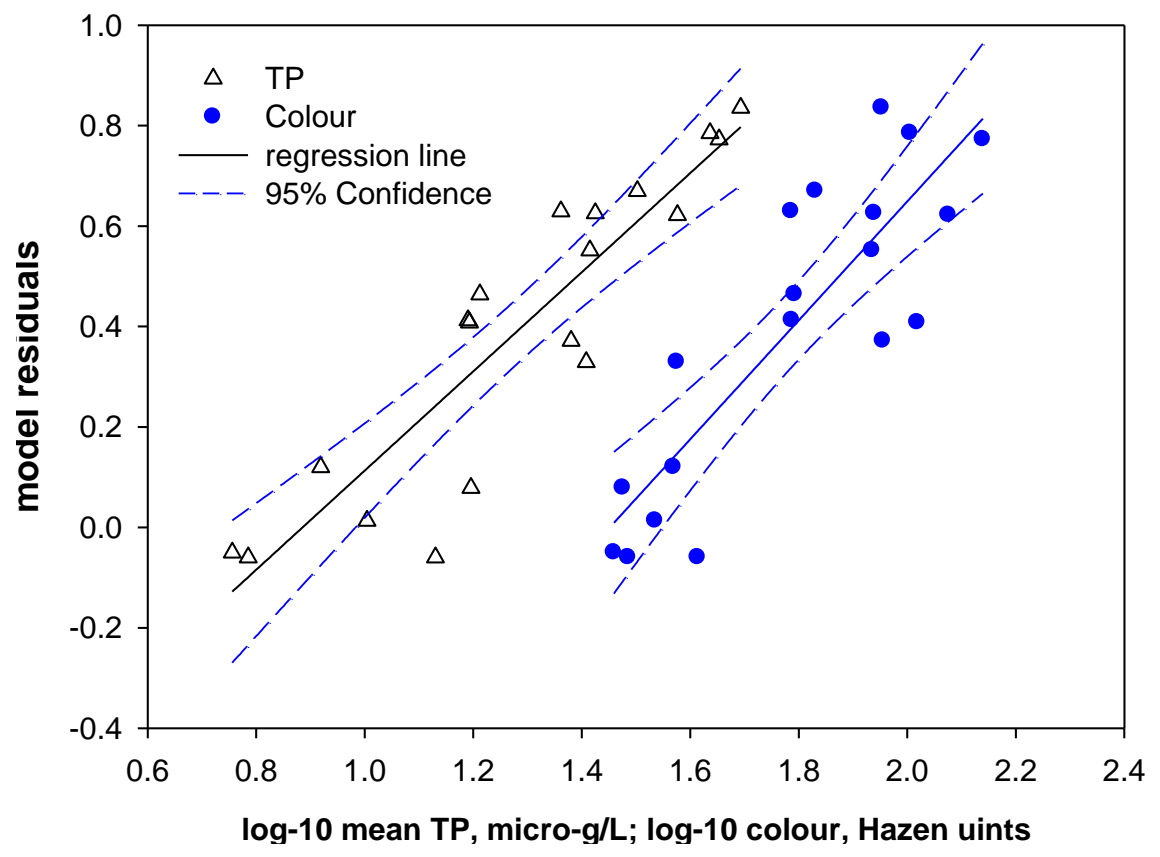

Figure 4. Plot of residuals from log10 predicted (non-humic model) vs measured mean TP against i) measured $\log 10$ TP and ii) colour in log10 Hazen unit equivalents for the 19 Scottish reference lochs. 


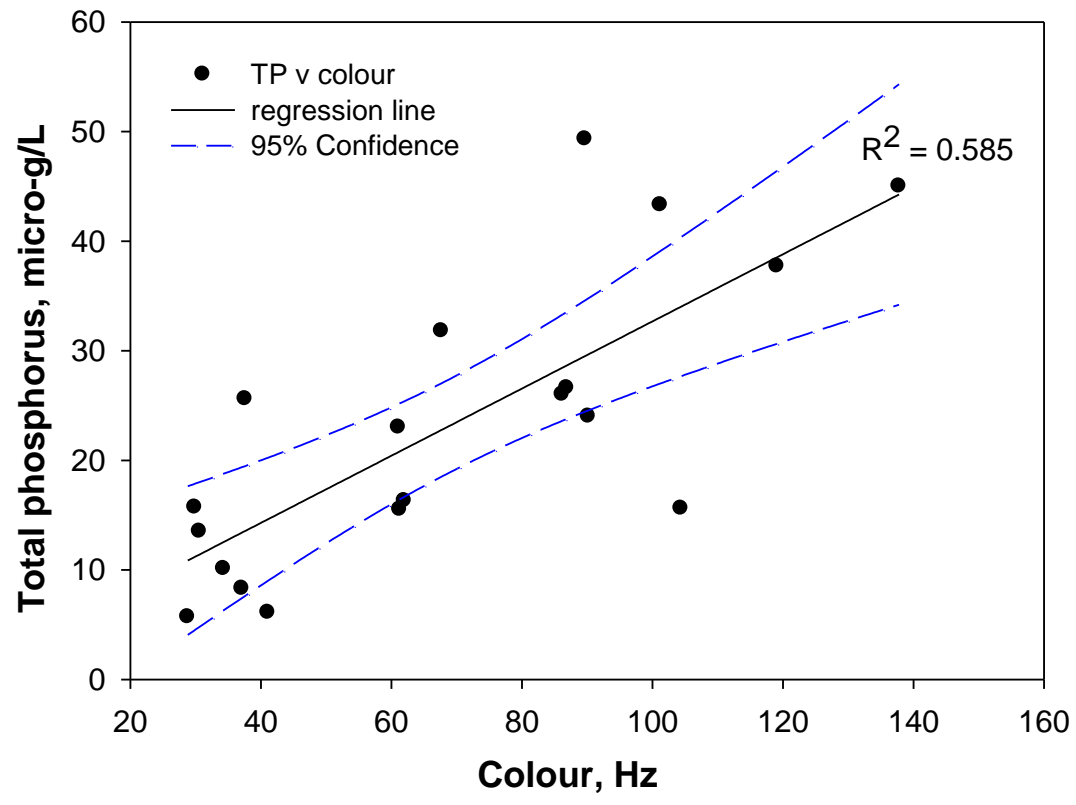

Figure 5 Regression of mean measured TP concentration vs colour (Hazen unit equivalents determined from DOC and UV-vis absorbance) for the 19 reference condition Scottish lochs; $p<0.0001$.

Table 1. Humic water classification systems as defined by different regimes

\begin{tabular}{ccc}
\hline & $\begin{array}{c}\text { GIG inter-calibration lake } \\
\text { type }^{*}\end{array}$ & Scottish Directions 2009 $^{\dagger}$ \\
\hline units & Hazen $(\mathrm{Hz})$, & Annual mean dissolved organic \\
& $\mathrm{mgPt} / \mathrm{L}$ & carbon (DOC), $\mathrm{mg} / \mathrm{L}$ \\
Non-humic & $<30$ & $<5$ \\
Humic & $>30$ & $\geq 5$ \\
${ }^{*}$ Van de Bund et al., 2004 & ${ }^{\dagger}$ Scottish Government 2009
\end{tabular}


Table -2: Geographical and feature information for the reference condition lochs used in the study

\begin{tabular}{|c|c|c|c|c|c|c|c|c|c|}
\hline Site & Easting & Northing & $\begin{array}{c}\text { GB- } \\
\text { WBID }^{1}\end{array}$ & UK NGR & $\begin{array}{c}\text { Mean } \\
\text { depth }(\mathrm{m})\end{array}$ & $\begin{array}{c}\text { Altitude } \\
(\mathrm{m})\end{array}$ & $\begin{array}{l}\text { Annual mean } \\
\text { colour }(\mathrm{Hz})^{2}\end{array}$ & $\begin{array}{c}\text { mean } \\
\text { alkalinity } \\
\text { (m equiv./l) }\end{array}$ & $\mathrm{MEI}^{3}$ \\
\hline Loch Fada, North Uist & 89063 & 870610 & 14627 & NF 8906370610 & 3.1 & 8 & 41.1 & 0.0481 & 0.016 \\
\hline Loch More, Caithness & 307700 & 946530 & 4672 & ND 0770046530 & 1.27 & 116 & 119.1 & 0.1514 & 0.119 \\
\hline Loch Ascaig, North Highlands & 284930 & 925660 & 8945 & NC 8493025660 & 4.8 & 135 & 86.9 & 0.1369 & 0.029 \\
\hline Loch Arnol, Isle of Lewis & 130000 & 948800 & 4156 & NB 3000048800 & 5.25 & 2 & 90.2 & 0.236 & 0.045 \\
\hline Housa Water, Wester Skeld, Shetland & 428700 & 1144200 & 1403 & HU 2870044200 & 3.51 & 47 & 104.4 & 0.0613 & 0.017 \\
\hline Loch a Chlachain, Isle of Lewis & 136160 & 932420 & 7308 & NB 3616032420 & 1.68 & 67 & 101.2 & 0.063 & 0.038 \\
\hline Loch Leir, North Highlands & 295791 & 945967 & 4819 & NC 9579145967 & 4.59 & 174 & 67.7 & 0.1996 & 0.043 \\
\hline Loch Gaineimh, North Highlands & 305162 & 947339 & 4513 & ND 0516247339 & 4.49 & 118 & 137.8 & 0.2644 & 0.059 \\
\hline Lochan Dubh nan Geodh, North Highlands & 306004 & 947508 & 4340 & ND 0600447508 & 4.83 & 136 & 61.1 & 0.0721 & 0.015 \\
\hline Loch Eileanach, North Highlands & 307138 & 946893 & 4329 & ND 0713846893 & 4.79 & 127 & 62 & 0.0821 & 0.017 \\
\hline Loch a Cherigal, North Highlands & 310095 & 948494 & 4188 & ND 1009548494 & 4.45 & 118 & 86.2 & 0.2245 & 0.050 \\
\hline Loch na Seilge, North Highlands & 291753 & 958779 & 2580 & NC 9175358779 & 5.04 & 115 & 61.3 & 0.1153 & 0.023 \\
\hline Loch of Girlsta, Shetland & 443200 & 1152200 & 1271 & HU 4320052200 & 9.6 & 28 & 37.1 & 0.1506 & 0.016 \\
\hline Loch of Burraland, Northmavine, Shetland & 434100 & 1174800 & 781 & HU 3410074800 & 1.42 & 27 & 29.9 & 0.4689 & 0.330 \\
\hline Loch of North-house, Clousta, Shetland & 432400 & 1155200 & 1170 & HU 3240055200 & 2.01 & 28 & 37.6 & 0.4755 & 0.237 \\
\hline Grass Water, West Burrafirth, Shetland & 428342 & 1153527 & 1250 & HU 2834253527 & 0.91 & 8 & 30.6 & 0.3876 & 0.426 \\
\hline Fugla Water, Lunna, Shetland & 450900 & 1171900 & 838 & HU 5090071900 & 3.4 & 25 & 89.7 & 0.0889 & 0.026 \\
\hline Loch of Gonfirth, Shetland & 438500 & 1162200 & 999 & HU 3850062200 & 3.72 & 128 & 28.8 & 0.1132 & 0.030 \\
\hline Loch of Flatpunds, West Mainland, Shetland & 424600 & 1152000 & 1291 & HU 2460052000 & 3.57 & 25 & 34.3 & 0.3543 & 0.099 \\
\hline
\end{tabular}

1. Great Britain lake water body identifier (GB-WBID)

2. Colour in Hazen units was calculated from the available colour (absorbance at $400 \mathrm{~nm}$ ) data or DOC data (by first converting to absorbance at $400 \mathrm{~nm}$ )

3. morphoedaphic index: alkalinity (m equiv./l)/ mean depth $(\mathrm{m})$ 


\section{Supplementary Information Files}

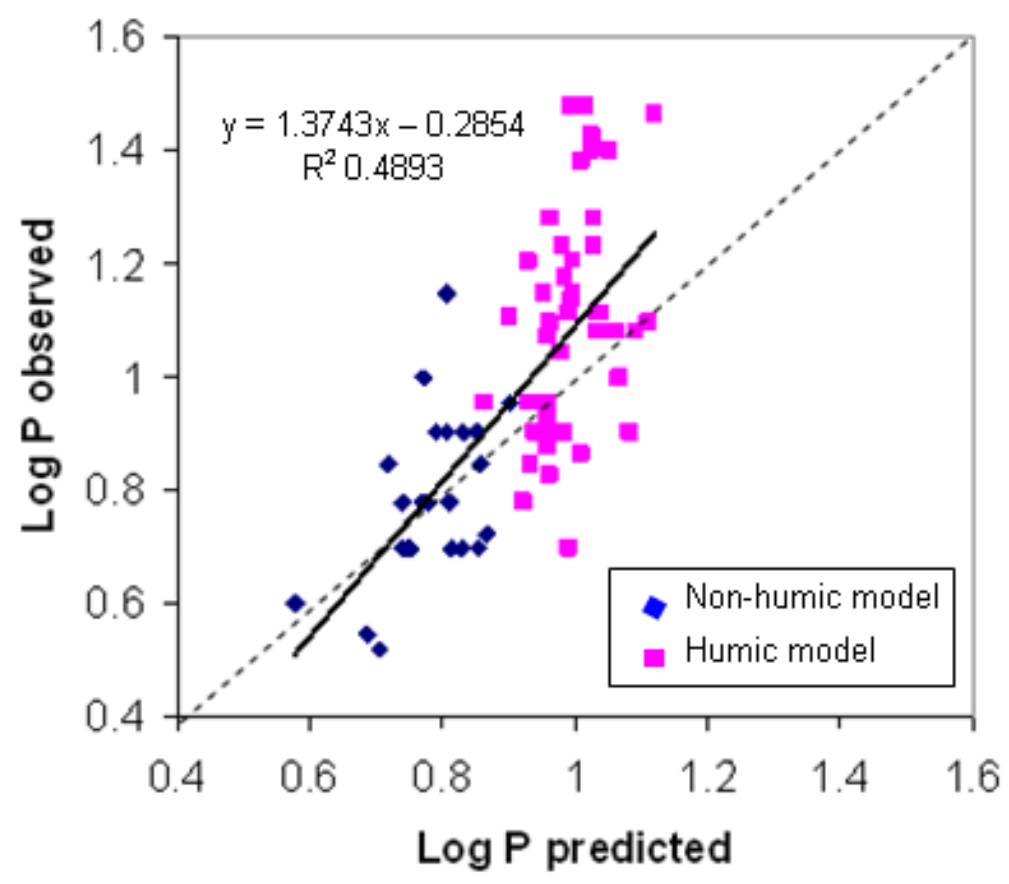

\section{Supplementary Information Figure 1 (Sup. Inf. Fig. 1)}

Log10 observed mean total phosphorus (TP) versus log10 predicted TP (humic and non-humic water models as appropriate for individual lakes) for 69 Finnish lakes. Solid line is the regression through all data, dotted line is the theoretical 1:1 relationship. Data from Heikki Mykrä, Ministry of the Environment, Finland, pers comm. of unpublished data 2008. 